\title{
Exploração e utilização do potencial madeireiro da Caatinga no município de Aurora - estado do Ceará
}

\author{
Amanda Pereira de Souza ${ }^{1}$, Francisco Carlos Pinheiro da Costa ${ }^{1}$, Rosana Ferreira \\ de Alencar $^{1} \&$ Silvio Felipe Barbosa Lima ${ }^{1,2,3}$
}

(1) Universidade Federal de Campina Grande, Centro de Formação de Professores, Unidade Acadêmica de Ciências Exatas e da Natureza, Rua Sérgio Moreira de Figueiredo, Casas Populares, Cajazeiras 58900000, Paraíba, Brasil. E-mail: E-mail: francisco.carlos@ufcg.edu.br, roferreiraalencar@gmail.com

(2) Universidade Federal da Paraíba - Campus I, Centro de Ciências Exatas e da Natureza, Departamento de Sistemática e Ecologia, Programa de Pós-Graduação Ciências Biológicas (Zoologia), Cidade Universitária, João Pessoa 58051-900, Paraíba, Brasil. E-mail: silvio.lima@ufcg.edu.br

(3) Universidade Federal da Paraíba - Campus II, Centro de Ciências Agrárias, Departamento de Ciências Biológicas, Programa de Pós-Graduação em Biodiversidade, Cidade Universitária, Areia 58397-000, Paraíba, Brasil.

Souza A.P., Costa F.C.P., Alencar R.F. \& Lima S.F.B. (2018) Exploração e utilização do potencial madeireiro da Caatinga no município de Aurora, estado do Ceará. Pesquisa e Ensino em Ciências Exatas e da Natureza, 2(2): 158-168. http://dx.doi.org/10.29215/pecen.v2i2.1070

Editora acadêmica: Antonia Arisdélia F. M. Aguiar Feitosa. Recebido: 24 Abril 2018. Aceito: 06 Novembro 2018. Publicado: 28 Dezembro 2018.

Resumo: As espécies vegetais existentes na Caatinga constituem um importante potencial madeireiro e econômico regional. $\mathrm{O}$ presente trabalho teve como objetivo conhecer como acontece a extração e utilização de madeira da Caatinga no município de Aurora - estado do Ceará, bem como as concepções de agricultores, marceneiros, escultores, luthier e proprietários de pizzaria e padaria quanto à origem e os impactos ambientais causados pela exploração desse recurso. A metodologia constou de aplicação de questionário semiestruturado para obtenção de informações como a origem e formas de utilização da madeira e sistematização dos dados. Os dados obtidos mostraram que os entrevistados retiram a madeira da Caatinga de forma predatória mesmo reconhecendo os riscos da extração, sendo esta usada para diversos fins, como a fabricação de móveis, portas, esculturas, instrumentos, cercas, além de ser utilizada como combustível para atividades cotidianas e para alimentar padarias e pizzarias. As espécies mais citadas foram: Mimosa tenuiflora (jurema-preta), Croton sonderianus (marmeleiro), Mimosa caesalpiniifolia (sabiá), Amburana cearensis (cumaru), Combretum leprosum (mufumbo), Myracrodruon urundeuva (aroeira) e Handroanthus impetiginosus (pau-d'arco). Os resultados obtidos apontam para a necessidade da implantação de ações voltadas para a fiscalização e controle da exploração da vegetação da Caatinga como também de orientações de manejos adequados desse importante recurso natural.

Palavras chave: Etnobotânica, recursos vegetais, produtos madeireiros, Semiárido.

\section{Exploitation and use of the Caatinga wooden potential in the municipality of Aurora, state of Ceará}

Abstract: Plant species of the Caatinga have considerable logging and economic potential. This paper addresses the extraction and use of Caatinga wood in the municipality of Aurora (state of Ceará, Brazil) as well as residents' conceptions regarding the origins and environmental impacts of the exploitation of this resource. A semi-structured questionnaire was used to obtain information on the origin and the forms of wood used. The data showed that, even when recognizing the risks of these actions, the interviewees extract wood from the Caatinga in a destructive manner, which is used for making furniture, doors, sculptures, instruments and fences as well as for fuel in cooking activities in homes, bakeries and pizzerias. The following species were more cited: Mimosa tenuiflora (jurema-preta), Croton sonderianus (marmeleiro), Mimosa caesalpiniifolia (sabiá), Amburana cearensis (cumaru), Combretum leprosum (mufumbo), Myracrodruon urundeuva (aroeira) and Handroanthus impetiginosus (pau-d'arco). The results point to the 
need for implementation of actions for the supervision and control of the exploitation of the Caatinga vegetation as well as adequate management guidelines for this important natural resource.

Key words: Ethnobotany, plant resources, wood products, Semiarid.

\section{Introdução}

A Caatinga é um domínio fitogeográfico brasileiro e como todas as áreas semiáridas do mundo, apresenta um longo período de estiagem e chuvas irregulares (Prado 2003). O nordeste brasileiro é em sua maior parte coberto pela Caatinga que compreende aproximadamente $844.453 \mathrm{~km}^{2}$ e cerca de $11 \%$ do território nacional, incluindo os estados de Maranhão, Piauí, Ceará, Rio Grande do Norte, Pernambuco, Paraíba, Alagoas, Sergipe, Bahia e o norte de Minas Gerais (IBGE 2004).

Segundo Pennington et al. (2009), a vegetação predominante da Caatinga é a savana tropical sazonalmente seca com um mosaico de fisionomias. A heterogeneidade fisionômica pode estar relacionada com as características geomorfológicas e ambientais, estando grande parte $(70 \%)$ inserida sobre o escudo cristalino e outra porção sobre bacias sedimentares $(30 \%)$, com uma variação no relevo entre 300 e 500 metros acima do nível do mar, podendo atingir mais de 1000 metros em algumas regiões (Andrade-Lima 1982; Cole 1986). A vegetação é composta principalmente por um estrato arbustivo-arbóreo que forma um dossel contínuo e baixo, na maioria das vezes, com modificações adaptativas para resistir às condições climáticas com longos períodos de seca e pluviosidade irregular (Maia 2004; Sampaio 2010). Apesar de tais fatores limitantes, a Caatinga apresenta uma considerável diversidade florística e faunística, com mais de 6000 espécies vegetais e de fungos, além de 1060 espécies de vertebrados (Leal et al. 2003; BFG 2018), destacando-se as angiospermas por conter um elevado índice de endemismo (20\%) (Giulietti 2003; BFG 2018), configurando-se assim num universo imenso a ser estudados e explorado.

No entanto, a diversidade da Caatinga assim como de outros ecossistemas brasileiros está severamente ameaçada pelos desmatamentos e queimadas oriundos das ações antrópicas que impactam não somente o componente florístico, mas também a fauna que dela depende, configurando-se em um dos biomas mais degradados do Brasil (Myers et al. 2000). Como consequência da exploração perene dos recursos vegetais da Caatinga, atualmente, há extensas áreas suscetíveis ao processo de desertificação, com solos erodidos e improdutivos (Lima et al. 2011). Além destes fatores estruturais, a utilização inadequada dos recursos oferecidos pela Caatinga em um grau que supera a capacidade de recuperação natural, pode acarretar na perda da biodiversidade, o que acaba ocasionando crescentes desequilíbrios ambientais (EMBRAPA 2007).

Segundo dados do MMA (2007), 46\% da área da Caatinga já foi alterada pelas atividades antrópicas ocasionando uma diminuição de sua biodiversidade, estando apenas cerca de $1 \%$ de seu patrimônio protegido em unidades de Proteção Integral. De acordo com Santana (2003), o nível de degradação das áreas de Caatinga é preocupante, visto que essa região sofre historicamente com o descaso e falta de políticas públicas que possam evitar o crescente processo de desertificação que está se instalando na região e dificilmente será revertido, agravando ainda mais os problemas sociais já existentes.

O processo de degradação da Caatinga, assim como dos demais biomas do Brasil, está intimamente relacionado principalmente à exploração e utilização da madeira como matériaprima para diversos fins ao longo da história (EMBRAPA 2007), sobretudo com o crescente aumento da densidade populacional. No setor primário, por exemplo, tem-se a exploração para subsistência de lenha, estacas para cercado, produção de carvão vegetal, bem como a comercialização (Ramos et al. 2014; Albuquerque et al. 2017). Em outros setores da economia, a madeira oriunda da Caatinga é empregada na construção civil, fabricação de móveis e produtos manufaturados, como instrumentos musicais e esculturas, além de alimentar fornos de padarias e pizzarias (Gomes et al. 2007). 
Economicamente, os recursos florestais da Caatinga são bastante atrativos para os setores madeireiros, apresentando inúmeras espécies potenciais (e.g., cumaru, imburana, ipê pau-d'arco e sipaúba) destinadas a confecção de portas, janelas, cancelas e móveis em geral. Além destas, outras espécies como angico, aroeira, baraúna e jurema são comumente utilizadas como estacas, moirões, linhas, ripas e na produção de carvão por diversos moradores da zona rural que praticam atividades agrícolas e retiram tais madeiras para cercar seus terrenos, assim como para comercializar para pizzarias e padarias (EMBRAPA 2007).

Para os utilitários dos recursos vegetais, um dos pontos positivos é a aquisição a baixo custo da madeira que, em sua maioria, decorre da extração ilegal. A ausência de uma fiscalização eficaz faz com que o setor extrativista desmate grandes áreas ao invés de realizar o uso sustentável, pois o reflorestamento não traria retorno financeiro tão rápido quanto a extração em áreas adjacentes onde há vegetação em ponto de corte (Costa \& Mitja 2010). Nesse sentido, faz-se necessário políticas públicas para mitigar os efeitos da degradação ambiental no semiárido brasileiro. Segundo Botrel et al. (2006), a população que se beneficia dos recursos naturais com a retirada da madeira para fins econômicos não tem se preocupado com a preservação de tais recursos, mostrando uma necessidade urgente de sensibilização para a conservação do meio ambiente. Neste aspecto, o município de Aurora, estado do Ceará, assemelha-se a muitos municípios do interior do Brasil, onde a madeira retirada da Caatinga é usada para fabricação de móveis, obras de arte, portas, janelas, cercas, lenha para uso geral e produção de carvão, causando sérios danos ao meio ambiente.

Neste contexto, o presente trabalho tem como objetivo diagnosticar as espécies de madeira nativas da Caatinga utilizadas como matéria-prima no município de Aurora, bem como a percepção dos moradores locais sobre os possíveis danos causados ao meio ambiente por conta da exploração predatória do recurso.

\section{Material e Métodos}

\section{Área de estudo}

O estudo foi realizado no município de Aurora, Cariri cearense, localizada na região nordeste do Brasil (Figura 1), a qual possui $885.83 \mathrm{~km}^{2}$ de extensão territorial e cerca de 24.602 habitantes. O município apresenta clima tropical quente semiárido, pluviosidade média de 884.9 $\mathrm{mm}$, relevo do tipo depressão sertaneja e solos Bruno não cálcico, litólicos e podzólico vermelhoamarelo (Viana et al. 2015).

A principal atividade econômica é a agricultura de subsistência, com a plantação de feijão, milho, mandioca e arroz, além de monoculturas de algodão, cana-de-açúcar, castanha de caju e frutas diversas. Na pecuária extensiva destaca-se a criação de bovinos, ovinos, caprinos e suínos. No extrativismo vegetal é feita a retirada de madeira para a produção de carvão vegetal, lenha e construção de cercas com estacas (Brandão \& Feitosa 1998).

\section{Classificação e sujeitos da pesquisa}

Seis marceneiros (Figura 2A-B), um escultor (Figura 2C), um luthier (Figura 2D), um proprietário de padaria e um proprietário de pizzaria (Grupo I) foram entrevistados na zona urbana da cidade de Aurora. Vinte (20) agricultores (Grupo II) também foram entrevistados na zona rural, a partir de três sítios distintos: Cachoeira (seis entrevistados), Logradouro (quatro entrevistados) e Vazantes (dez entrevistados).

A abordagem desta pesquisa é de caráter quantitativo e qualitativo, com levantamento de dados a partir de questionários e análise das concepções dos entrevistados referente ao tema da pesquisa. Para Silveira \& Córdova (2009) a pesquisa quantitativa tem suas raízes no pensamento positivista lógico e tende a enfatizar o raciocínio dedutivo, as regras da lógica e os atributos mensuráveis da experiência humana. Já a pesquisa qualitativa não se preocupa com representatividade numérica, mas sim, com o aprofundamento da compreensão. Segundo 
Fonseca (2002), a pesquisa qualitativa se preocupa com aspectos da realidade que não podem ser quantificados, centrando-se na compreensão e explicação da dinâmica das relações sociais.

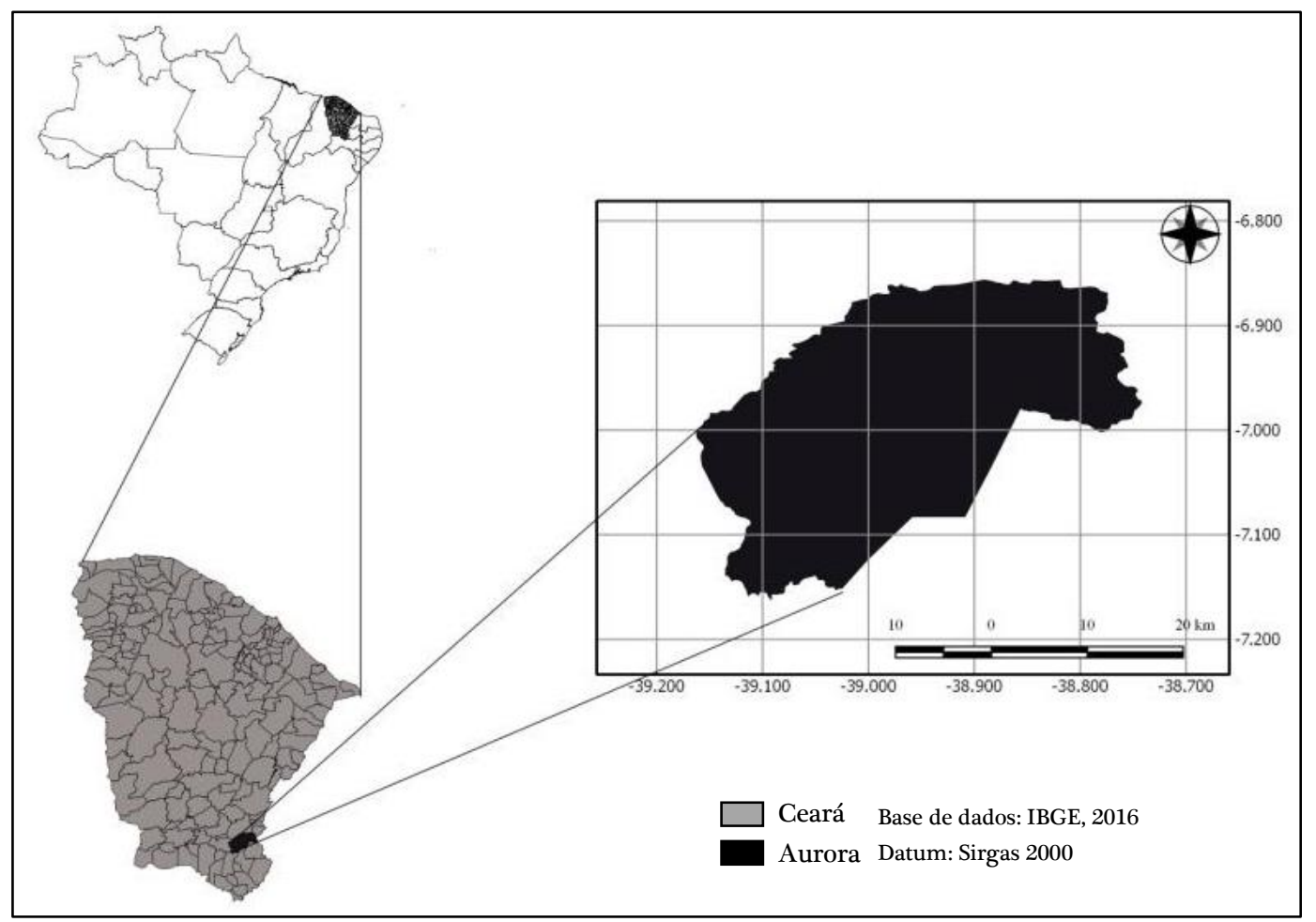

Figura 1. Localização geográfica do município de Aurora, estado do Ceará.

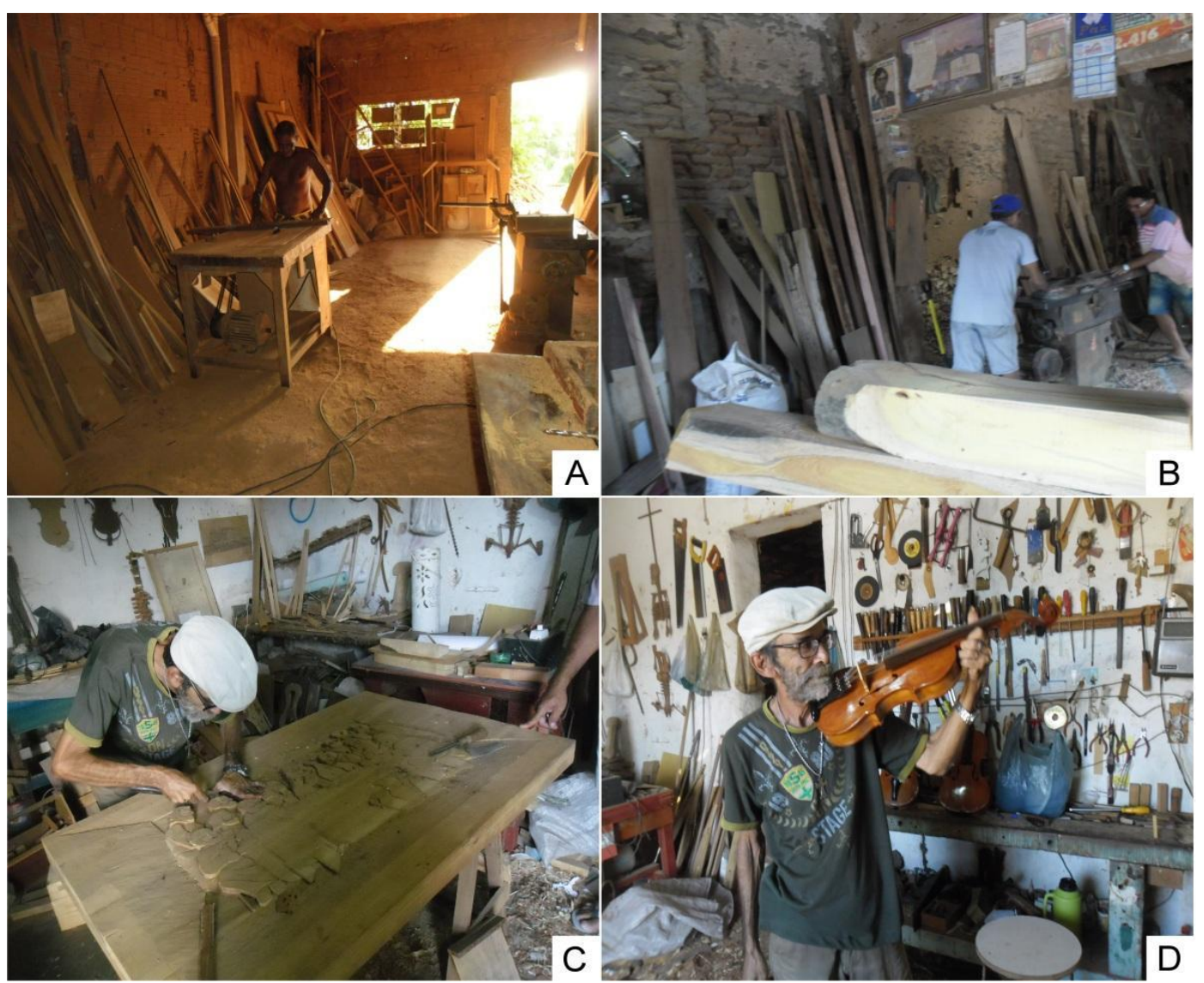

Figura 2. Sujeitos participantes da pesquisa entrevistados na cidade de Aurora: A-B. Marceneiros, G. Escultor, D. Luthier. 
Quanto aos procedimentos, trata-se de uma pesquisa de campo, a qual caracteriza as investigações para além da pesquisa bibliográfica e/ou documental, coletando dados junto a pessoas com base em diversos tipos de instrumentos de pesquisa (ex-post-facto, pesquisa ação, pesquisa participante, questionários, etc.).

\section{Técnicas de coleta de dados}

A coleta de dados foi realizada a partir de entrevistas [após aprovação do projeto no Comitê de Ética (CAAE: 66137617.8.0000.557)] com base na aplicação de questionários, durante visitas realizadas a agricultores de três sítios do município (Cachoeira, Logradouro e Vazantes), bem como a marcenarias, casa de marceneiros, escultor, luthier, uma pizzaria e padaria da localidade. Todas as entrevistas foram realizadas mediante a autorização e assinatura do TCLE (Termo de Consentimento Livre e Esclarecido), buscando-se obter dados referentes às espécies madeireiras mais usadas por estes setores mencionados, no intuito de reconhecer a importância da madeira para a economia local e as concepções dos mesmos sobre a prática de exploração madeireira.

\section{Resultados}

Oito (8) famílias e quatorze (14) espécies de plantas arbustivas-arbóreas foram identificadas por serem exploradas e utilizadas pela população do município de Aurora devido ao seu potencial madeireiro (Tabela 1).

Para o Grupo I, canafístula, catingueira, cumaru, imburana, ipê, jurema-preta, mofumbo, pau-d'arco e sipaúba (Tabela 1) são as plantas arbustivas-arbóreas oriundas da Caatinga cuja madeira estão entre as mais utilizadas nas atividades laborais (Figura 3). Estas e outras espécies são retiradas de forma predatória e, segundo os entrevistados, não há um plano de manejo ou recuperação das áreas exploradas. Apesar do conhecimento sobre o estágio avançado de degradação da Caatinga, os entrevistados continuam retirando madeira indiscriminadamente do bioma. Além da exploração do potencial madeireiro local, os entrevistados informaram também utilizar madeiras procedentes de outras regiões, porém sem conhecer o local original de extração da madeira adquirida.

O Grupo I, mesmo sem especificar quais os problemas que envolvem a exploração predatória dos recursos vegetais da Caatinga, reconhece que suas atividades são danosas ao meio ambiente. Os componentes deste grupo afirmaram que a supressão madeireira está acabando com a biodiversidade, refletindo nos longos períodos de estiagem e que seria menos impactante se houvesse um plano de manejo ou mesmo a reintrodução das espécies suprimidas. Atualmente, grandes áreas da vegetação local estão recobertas apenas por capim, uma vez que já foram desmatadas em grande escala para o pastoreio e alimentar o comércio local.

Em termos de viabilidade econômica, 50\% dos entrevistados do Grupo I relataram que a retirada da madeira gera emprego e renda nos vários setores comerciais, movimentando a economia local. Para 50\% dos entrevistados, na maioria das vezes, a exploração do potencial madeireiro da Caatinga é o único meio de sustento da família, sendo a madeira utilizada para diversos fins, os quais não foram especificados. Um ponto positivo destacado, segundo os entrevistados, seria a relação custo-benefício, pois a utilização da madeira retirada da Caatinga é menos oneroso do que a importação do material proveniente de outras regiões. Além deste aspecto, também foi citado pelos donos de padarias e uma pizzaria o custo-benefício dos fornos à lenha em detrimento aos fornos a gás.

A utilização mensal de madeira oriundas da Caatinga varia, segundo os entrevistados, de acordo com a demanda. O escultor e luthier utilizam cerca de $0.5 \mathrm{~m}^{3}$ de madeira de espécies locais, como o cumaru e imburana, além da madeira de outras espécies vegetais cuja procedência é desconhecida. Já para o funcionamento dos fornos das padarias e de uma pizzaria, os entrevistados informaram utilizar cerca de $15 \mathrm{~m}^{3}$ de madeira de espécies como jurema, mufumbo e sipaúba. 
Para o Grupo II, aroeira, catingueira, cumaru, frei-jorge, jurema-preta, marmeleiro, mofumbo, mororó, sabiá e sipaúba (Tabela 1) estão entre as espécies vegetais mais comumente extraídas de suas propriedades (Figura 3). A extração ocorre no período da "broca" compreendido entre junho e setembro em que a prática é muito comum em todo o nordeste do Brasil. Indubitavelmente, as práticas no referido período provocam danos irreversíveis ao ecossistema, pois ocorre o desmatamento seguido de fogo (broca) podendo causar o empobrecimento do solo matando os microrganismos existentes, além de resultar na maioria dos incêndios que destroem parte da vegetação da Caatinga todos os anos.

Tabela 1. Espécies nativas do município de Aurora citadas e utilizadas pelos entrevistados com potencial madeireiro $\left(\mathrm{N}^{\circ}=\right.$ número de vezes citadas).

\begin{tabular}{|c|c|c|c|}
\hline Família & Nome científico & Nome vernáculo & $\mathbf{N}^{\circ}$ \\
\hline Boraginaceae & Cordia trichotoma (Vell.) Arráb. ex Steud. & Frei-jorge & 01 \\
\hline Burseraceae & Commiphora leptophloeos (Mart.) J.B.Gillett & Imburana & 01 \\
\hline Fabaceae & Bauhinia cheilantha (Bong.) Steud. & Mororó & 01 \\
\hline Fabaceae & Poincianella pyramidalis Tulasne \& Louis René & Catingueira & 02 \\
\hline Combretaceae & Combretum glaucocarpum Mart. & Sipaúba & 02 \\
\hline Fabaceae & Senna spectabilis (DC.) H.S. Irwin \& Barneby & Canafístula & 03 \\
\hline Bignoniaceae & Tabebuia aurea (Silva Manso) Benth. \& Hook.f. ex S.Moore & Ipê & 03 \\
\hline Anacardiaceae & Myracrodruon urundeuva Allemão & Aroeira & 05 \\
\hline Bignoniaceae & Handroanthus impetiginosus (Mart. ex DC.) Mattos & Pau-d'arco & 05 \\
\hline Combretaceae & Combretum leprosum Mart. & Mofumbo & 06 \\
\hline Fabaceae & Amburana cearensis (Allemão) A.C.Sm. & Cumaru & 07 \\
\hline Fabaceae & Mimosa caesalpiniifolia Benth. & Sabiá & 09 \\
\hline Euphorbiaceae & Croton sonderianus Müll.Arg. & Marmeleiro & 14 \\
\hline Fabaceae & Mimosa tenuiflora (Willd.) Poir. & Jurema-preta & 22 \\
\hline
\end{tabular}

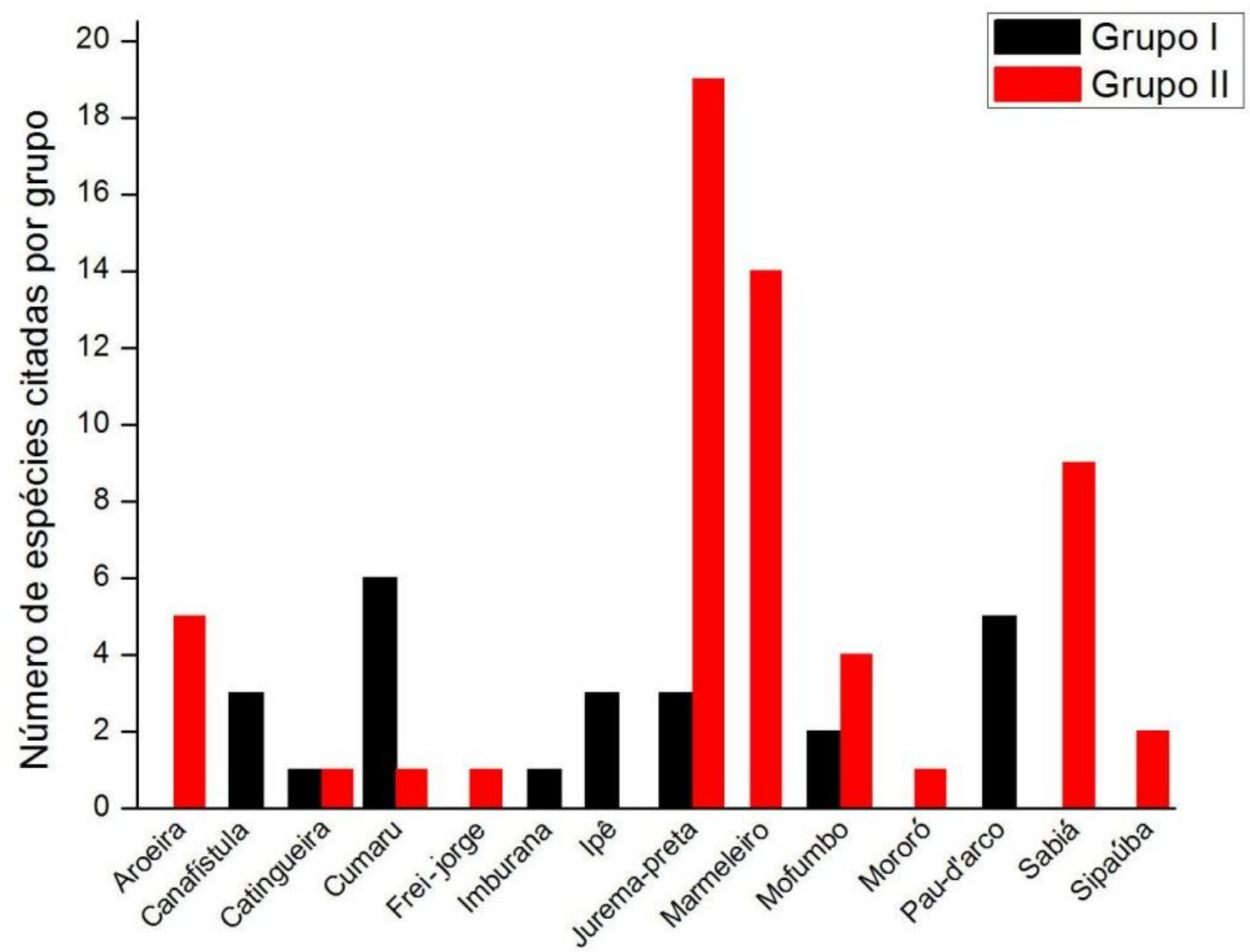

Figura 3. Espécies vegetais nativas da Caatinga citadas pelos Grupos I e II por serem utilizadas em suas atividades laborais. 
Segundo o Grupo II, a extração de recursos vegetais da Caatinga tem sido feita rotineiramente e, considerando-se a extensão da propriedade, varia entre um e 80 hectares. Ao longo dos anos, os integrantes do Grupo II perceberam ter havido um decréscimo da cobertura vegetal em detrimento a anos anteriores e acreditam que a situação da paisagem tende a piorar devido a ausência de medidas para atenuar os efeitos de degradação advindos da prática da "brocagem" (desmatamento seguido de fogo). Apenas 20\% dos entrevistados do Grupo II desenvolvem ações para minimizar os impactos da retirada da vegetação com base no reflorestamento das áreas exploradas, enquanto a maioria (70\%) não toma nenhuma providência. Uma pequena parcela dos entrevistados (10\%) afirmou que a vegetação nasce espontaneamente após o abandono das terras pelos antigos proprietários.

Os entrevistados que atuaram no reflorestamento das áreas locais desmatadas empregaram espécies nativas e exóticas. Dentre as espécies arbóreas nativas utilizadas no reflorestamento da vegetação da Caatinga do município de Aurora estão aroeira, pau-d'arco e sabiá, além de espécies naturalizadas com um grande histórico de utilização para este fim na região nordeste como a algaroba e leucena. $\mathrm{O}$ nim indiano é uma das espécies exóticas bem difundidas no nordeste do Brasil devido a sua adaptabilidade às condições edafo-climáticas da região e que vem sendo gradativamente utilizada em detrimento às nativas. Além desta, outros entrevistados alegaram fazer o reflorestamento utilizando plantas frutíferas.

Apesar do cenário de degradação ambiental no qual grande parte do município está submetida e que tem reduzido tanto a diversidade vegetal como animal na região de Aurora, $70 \%$ dos entrevistados relataram que no entorno do açude de abastecimento não há exploração dos recursos vegetais, sendo a temperatura no local mais amena, o solo mais fértil, além de haver uma maior diversidade animal.

Para os entrevistados, a supressão vegetal é uma prática danosa que está diretamente relacionada à degradação do meio ambiente. Apesar de serem contra esta prática, os moradores do município de Aurora exploram e utilizam o potencial madeireiro da região, para o sustento da família através da comercialização de lenha e/ou carvão bem como para a realização de atividades cotidianas como cozinhar e utilização de estacas para cercar seus terrenos.

Cumaru (25\%) e pau-d'arco (20\%) são as espécies vegetais nativas mais utilizadas nas marcenarias (Grupo I), tendo como finalidade a fabricação de cancelas, móveis e portas (Figura 3). Segundo os entrevistados, a utilização de tais espécies vegetais se dá pelo fato de possuírem diâmetro maior em relação as demais espécies citadas e, principalmente, por serem resistentes ao ataque de fungos e insetos xilófagos, como o cupim. Ambas também se destacam na confecção de instrumentos musicais e esculturas. Já a jurema-preta (conforme $33 \%$ dos entrevistados), marmeleiro (segundo 25\% dos entrevistados) e sabiá (de acordo com 16\% dos entrevistados) são as espécies nativas mais utilizadas pelo Grupo II, sendo a sua madeira empregada, principalmente, na construção de cercas e como lenha para alimentar fogões. Jurema-preta e marmeleiro se sobressaem em detrimento as demais por se estabelecerem com maior facilidade em ambientes perturbados após desmatamento, uso e sucessivo abandono, formando grandes populações.

\section{Discussão}

Em Aurora bem como em outras cidades de pequeno porte do interior do nordeste, a disponibilidade de empregos oferecidos é bastante limitada. Por conta disto, o potencial madeireiro da Caatinga sempre foi bastante explorado pelas populações locais tendo em vista a dependência econômica dos residentes, onde a retirada de madeira direta ou indiretamente significa aquisição de renda e geração de economia local, principalmente entre os grupos aqui pesquisados. Ramos \& Albuquerque (2012) verificaram que a maior parte dos moradores entrevistados de uma comunidade rural da Caatinga, no município de Soledade (Paraíba) usa lenha em suas residências para cozinhar alimentos alegando o alto custo do gás de cozinha e a facilidade para a obtenção de lenha. Conforme Ramos et al. (2014) a dependência dos recursos madeireiros para a subsistência humana está diretamente relacionada ao baixo poder aquisitivo 
de determinadas populações, as quais necessitam utilizar o recurso no cotidiano das famílias para diversos fins.

Há uma considerável riqueza de plantas explorada por residentes de comunidades da Caatinga devido ao seu potencial madeireiro (Ramos et al. 2008a,b; Ramos \& Albuquerque 2012). Dentre as famílias e espécies arbustivas-arbóreas da Caatinga utilizadas pelos grupos aqui entrevistados e também por residentes da comunidade do Riachão de Malhada de Pedra estão: Anacardiaceae (Myracrodruon urundeuva), Fabaceae (Bauhinia cheilantha e Poincianella pyramidalis) e Euphorbiaceae (Croton) (ver Ramos et al. 2008a,b). No entanto, os moradores desta comunidade exploram e utilizam o potencial madeireiro da região, principalmente como lenha e na produção de carvão (Ramos et al. 2008a,b), enquanto que os residentes de Aurora usam a madeira também em outras atividades laborais. Poincianella pyramidalis está entre as espécies mais citadas pela utilização por moradores de Riachão de Malhada de Pedra (Ramos et al. 2008a,b). De acordo com Ramos \& Albuquerque (2012), Poincianella pyramidalis, Mimosa tenuiflora, Myracrodruon urundeuva e Commiphora leptophloeos estão entre as espécies frequentemente estocadas entre residentes de comunidades rurais no município de Soledade (Paraíba) para a utilização como lenha. Em contraste a estes estudos, Commiphora leptophloeos, Poincianella pyramidalis e Myracrodruon urundeuva foram as plantas menos citadas por sua utilização entre os residentes de Aurora.

Os resultados da pesquisa mostraram que, para todos os entrevistados dos dois grupos, a madeira é essencial no que diz respeito ao subsídio familiar e manutenção dos setores locais como as marcenarias e ateliê, bem como para os proprietários de terras que utilizam o recurso para confecção de estacas para cercar seus terrenos e lenha para os fogões. Adicionalmente, recursos madeireiros também são empregados em fornos à lenha de estabelecimentos comerciais tais como pizzarias e padarias. Os recursos madeireiros são utilizados por populações, sobretudo da Caatinga, para inúmeras finalidades, especialmente como lenha e para a construção de estruturas e confecção de artefatos (Albuquerque et al. 2012, 2017; Ramos et al. 2014). Estudos têm enfatizado que os recursos e produtos madeireiros são de suma importância para a subsistência de populações locais, no entanto, havendo escassez de dados etnobotânicos sistemáticos sobre o uso doméstico da madeira (Ramos et al. 2010, 2014, 2015; Albuquerque et al. 2017), principalmente como fonte energética no bioma Caatinga (Ramos et al. 2008b). Ramos \& Albuquerque (2012) identificaram 30 produtos madeireiros confeccionados por moradores do município de Soledade usualmente empregados como estacas, ripas, placas, lenha, enxada, picaretas e portões. Em Aurora, espécies vegetais com potencial madeireiro também são empregadas para a construção de portas, cercas e como lenha. Por outro lado, somente na área estudada, observou-se a utilização da madeira para a fabricação de instrumentos musicais e esculturas.

Nos dados coletados junto aos agricultores, observa-se que a cultura de exploração e utilização do potencial madeireiro do município de Aurora é transmitida por gerações, uma vez que os entrevistados possuem idade que variam de 24 a 81 anos, sendo que $45 \%$ deles estão na faixa etária de 60 anos e a maioria $(70 \%)$, reside na propriedade a mais de 40 anos, sendo muitas vezes difícil de interromper uma prática cotidiana comum em municípios brasileiros de pequeno porte e, em especial, na zona rural. Deste modo, faz-se necessária uma discussão sobre a importância da coletividade para o desenvolvimento de uma consciência ambiental e, consequente, modificação de traços culturais praticados ao longo das gerações (Faller et al. 2006).

Além da exploração madeireira, a "broca" realizada pelos agricultores para preparar a terra para o plantio aliada a monocultura torna o solo gradualmente estéril e improdutivo, causando a morte dos microrganismos responsáveis por sua fertilização. Outrossim, contribui para o processo erosivo do solo bem como para a desertificação, acarretando perdas consideráveis na biodiversidade da Caatinga (Albuquerque et al. 2001).

A Caatinga assim como outros domínios fitogeográficos do Brasil está em avançado estágio de degradação com poucos remanescentes conservados. O processo tem se intensificado através dos longos períodos de estiagem que a região tem enfrentado, sobretudo pela exploração 
e retirada de recursos naturais do bioma pela população local para a subsistência. A falta de fiscalização por meio dos órgãos ambientais e de conscientização ambiental da população acerca dos danos causados pela extração predatória da vegetação é também um dos principais problemas encontrados para inibir a ação antrópica negativa sobre o bioma. Diante desta problemática, percebe-se que o futuro depende das ações do presente.

Os resultados mostram a necessidade da criação e aplicação de projetos educacionais de cunho ambiental onde aliem teoria e prática, visando alcançar resultados concretos, priorizando atender as emergências cada vez mais acentuadas sobre a preservação da biodiversidade da Caatinga.

\section{Agradecimentos}

Aos avaliadores anônimos pela revisão crítica do manuscrito.

\section{Referências}

Albuquerque A.W., Lombardi Neto F. \& Srinivasan V.S. (2001) Efeito do desmatamento da Caatinga sobre as perdas de solo e água de um Luvissolo em Sumé (PB). Revista Brasileira de Ciências do Solo, 25(1): 10-17. DOI: 10.1590/S0100-06832001000100013

Albuquerque U.P., Araújo E.L., Castro C.C. \& Alves R.R.N. (2017) Chapter 11 - People and Natural Resources in the Caatinga (p. 303-334). In: Silva J.M.C., Leal I.R. \& Tabarelli M. (Eds). Caatinga: The Largest Tropical Dry Forest Region in South America. Switzerland: Springer. 482 p. DOI: 10.1007/978-3-319-68339-3

Albuquerque U.P., Araújo E.L., El-Deir A.C.A., Lima A.L.A., Souto A., Bezerra B.M., Ferraz E.M.N., Freire E.M.X., Sampaio E.V.S.B., Las-Casas F.M.G., Moura G.J.B., Pereira G.A., Melo J.G., Ramos M.A., Rodal M.J.N., Schiel N., Lyra-Neves R.M., Alves R.R.N., Azevedo-Júnior S.M., Telino Júnior W.R. \& Severi W. (2012) Caatinga Revisited: Ecology and Conservation of an Important Seasonal Dry Forest. The Scientific World Journal, 2012(Article ID 205182): 1-18. DOI: $10.1100 / 2012 / 205182$

Andrade-Lima D. (1982) Present day forest refuges in Northeastern Brazil (p. 245-254). In: Prance G.T. (Ed.). Biological Diversification in the Tropics. New York: Columbia University Press. $714 \mathrm{p}$.

BFG - The Brazil Flora Group (2018) Brazilian Flora 2020: Innovation and collaboration to meet Target 1 of the Global Strategy for Plant Conservation (GSPC). Rodriguésia, 69(4): 15131527.

Botrel R.T., Rodrigues L.A., Gomes L.J., Carvalho D.A. \& Fontes M.A.L. (2006) Uso da vegetação nativa pela população local no município de Ingaí, MG, Brasil. Acta Botanica Brasilica, 20(1): 143-156. DOI: 10.1590/S0102-33062006000100014

Brandão R.L. \& Feitosa F.A.C. (1998) Programa de recenseamento de fontes de abastecimento por água subterrânea no estado do Ceará: diagnóstico do município de Aurora. CPRM: Ministério de Minas e Energia. Disponível em: http://www.cprm.gov.br/ (Acessado em 26/06/2017).

Cole M.M. (1986) The Savannas: Biogeography and Geobotany. London: Academic Press. 438 p.

Costa J.R. \& Mitja D. (2010) Uso dos recursos vegetais por agricultores familiares de Manacapuru (AM). Acta Amazonica, 40(1): 49-58. DOI: 10.1590/S0044-59672010000100007

EMBRAPA - Empresa Brasileira de Pesquisa Agropecuária (2007) Preservação e uso da Caatinga: Embrapa Semiárido. Brasília, DF: Embrapa Informação Tecnológica. 39 p.

Evangelista A.R.S. (2011) O processo de desmatamento do bioma caatinga: riscos e vulnerabilidades socioambientais no território de identidade do sisal, Bahia. Revista geográfica de América Central (edição especial EGAL): 1-13.

Faller L.P., Zamberlam C.O. \& Abicht A.M. (2006) Percepção do cliente nos móveis fabricados com madeira reflorestada. São Paulo: XIII SIMPEP. 10 p.

Fonseca JJ.S. (2002) Metodologia da pesquisa científica. Fortaleza: UEC. 127 p. 
Galindo I.C.L., Ribeiro M.R., Santos M.F.A.V.S., Lima, J.F.W.F. \& Ferreira R.F.A.L. (2008) Relações solo-vegetação em áreas sob processo de desertificação no município de Jataúba, PE. Revista Brasileira de Ciência do Solo, 32(3): 1283-1296. DOI: 10.1590/S0100-06832008000300036

Giulietti A.M. (2003) Vegetação: áreas e ações prioritárias para a conservação da Caatinga (p. 113-131). In: Silva J.M.C., Tabarelli M., Fonseca M.T. \& Lins L.V. (Org.). Biodiversidade da Caatinga: áreas e ações prioritárias para a conservação. Ministério do Meio Ambiente: Universidade Federal de Pernambuco. 382 p.

Gomes J.J., Toledo Filho R.D., Nascimento J.W.B., Silva V.R. \& Nóbrega M.V. (2007) Características tecnológicas da Prosopis juliflora (Sw.) DC. e alternativas para uso racional. Revista Brasileira de Engenharia Agrícola e Ambiental, 11(5): 537-542. DOI: 10.1590/S141543662007000500015

IBGE - Instituto Brasileiro de Geografia e Estatística (2004) Mapa de Biomas do Brasil. Escala 1:5.000. Rio de Janeiro: Instituto Brasileiro de Geografia e Estatística (IBGE). Disponível em: https://www.ibge.gov.br/geociencias-novoportal/informacoes-ambientais/estudos-ambientais/1 5842-biomas.html?=\&t=downloads (Acessado em 19/10/2017).

Leal I.R., Tabarelli M. \& Silva J.M.C. (2003) Ecologia e Conservação da Caatinga. Recife: Ed. Universitária da UFPE. 822 p.

Lima R.C.C., Cavalcante A.M.B. \& Marin A.M.P. (2011) Desertificação e mudanças climáticas no semiárido brasileiro. Campina Grande: INSA-PB. 211 p.

Maia G.N. (2004) Caatinga: árvores e arbustos e suas utilidades. São Paulo: D\&Z Computação Gráfica e Editora. 413 p.

MMA - Ministério do Meio Ambiente (2007) Caatinga. Disponível em: http:// http://www.mma.gov.br/biomas/caatinga (Acessado em 22/06/2017).

Myers N., Mittermeier R.A., Mittermeier C.G., Fonseca G.A.B. \& Kent J. (2000) Biodiversity hotspots for conservation priorities. Nature, 403: 853-859.

Ndagijimana C., Pareyn F.G.C. \& Riegelhaupt E. (2015) Uso do solo e desmatamento da Caatinga: um estudo de caso na Paraíba e no Ceará - Brasil (p. 18-29). In: Pareyn F., Vieira J.L. \& Gariglio M.A. (Orgs.). Estatística Florestal da Caatinga. Recife: Associação Plantas do Nordeste. 140 p.

Paes J.B., Morais V.M., Lima C.R. \& Santos G.J.C. (2009) Resistência natural de nove madeiras do semiárido brasileiro a fungos xilófagos em simuladores de campo. Revista Árvore, 33(3): 511-520. DOI: 10.1590/S0100-67622009000300013

Pennington R.T., Lavin M. \& Oliveira-Filho A.T. (2009) Evolution, and ecology in the tropics: perscpectives from seasonally dry tropical forests. Annual Review of Ecology, Evolution, and Systematics, 40: 437-457.

Prado D.E. (2003) As Caatingas da América do Sul (p. 3-73). In: Leal I.R., Tabarelli M. \& Silva J.M.C. (Eds.). Ecologia e conservação da caatinga. Recife: Ed. Universitária da UFPE. 806 p.

Queiroz L.P. (2009) Leguminosas da Caatinga. Feira de Santana: Universidade Estadual de Feira de Santana. 467 p.

Ramos M.A. \& Albuquerque U.P. (2012) The domestic use of firewood in rural communities of the Caatinga: How seasonality interferes with patterns of firewood collection. Biomassa and Bioenergy, 39(2012): 147-158. DOI: 10.1016/j.biombioe.2012.01.003

Ramos M.A., Medeiros P.M. \& Albuquerque U.P. (2010) Métodos e técnicas a estudos etnobotânicos com recursos madeireiros (p. 329-350). In: Albuquerque U.P., Lucena R.F.P. \& Cunha L.V.F.C. (Orgs). Métodos e Técnicas na Pesquisa Etnobiológica e Etnoecológica. Volume 1. Série Estudos \& Avanços. Recife: NUPEEA. 558 p.

Ramos M.A., Cavalcanti M.C.B.T. \& Vieira F.J. (2014) Recursos madeireiros (p. 105-113). In: Albuquerque U.P. (Org.). Introdução a Etnobiologia. Recife: NUPEEA. 189 p.

Ramos M.A., Lucena R.F.P. \& Albuquerque U.P. (2015) What drives the knowledge and local uses of timber resources in human-altered landscapes in the semiarid region of northeast Brazil? International Journal of Sustainable Development \& World Ecology, 2015: 1-15. DOI: 10.1080/13504509.2015.1091796 
Ramos M.A., Medeiros P.M., Almeida A.L.S., Feliciano A.L.P. \& Albuquerque U.P. (2008a) Can wood quality justify local preferences for firewood in an area of caatinga (dryland) vegetation? Biomassa and Bioenergy, 32(2008): 503-509. DOI: 10.1016/j.biombioe.2007.11.010

Ramos M.A., Medeiros P.M., Almeida A.L.S., Feliciano A.L.P. \& Albuquerque U.P. (2008b) Use and knowledge of fuelwood in an area of Caatinga vegetation in NE Brazil. Biomassa and Bioenergy, 32(2008): 510-517. DOI: 10.1016/j.biombioe.2007.11.015

Sampaio E.V.S.B. (2010) Caracterização do bioma Caatinga: características e potencialidades (p. 27-42). In: Gariglio M.A., Sampaio E.V.S.B., Cestaro L.A. \& Kageyama P.Y. (Orgs). Uso sustentável e conservação dos recursos florestais da Caatinga. Brasília: Serviço Florestal Brasileiro. 368 p.

Santana A.C.A. (2003) Proteção legal da Caatinga. Dissertação de Mestrado, Programa Regional de Pós-Graduação em Desenvolvimento e Meio Ambiente. Universidade Federal de Sergipe, Aracajú, Sergipe.

Silva J.M.C., Barbosa L.C.F., Leal I.R. \& Tabarelli M. (2017) The Caatinga: Understanding the Challenges (p. 3-22). In: Silva J.M.C., Leal I.R. \& Tabarelli M. (Eds.) Caatinga: the largest Tropical Dry Forest region in South America. Switzerland: Springer Nature. 474 p.

Silveira D.T. \& Córdova F.P. (2009) Métodos de Pesquisa. Porto Alegre: Editora da UFRGS. 120 p.

Viana C.M.P., Sousa F.J., Lima K.A. \& Nascimento M.M.S. (2015) Perfil básico municipal 2015: Aurora. Instituto de Pesquisa e Estratégia Econômica do Ceará (IPECE). Disponível em: http://www.ipece.ce.gov.br/ (Acessado em 27/06/2017).

Zenid G.J. (2009) Madeira: uso sustentável na construção civil. São Paulo: Instituto de Pesquisas Tecnológicas - SVMA. 103 p. 